\title{
Predicting a Behavioral Profile for Pleasure Travelers on the Basis of
}

\section{Internet Use Segmentation}

\author{
Mark A. Bonn \\ Florida State University \\ H. Leslie Furr \\ Georgia Southern University \\ Alex M. Susskind \\ Cornell University
}

Final version published May 1999 in Journal of Travel Research, Vol. 37, 333-340

Author Note

Mark A. Bonn, Ph.D., is an associate professor in the Department of Hospitality Administration at Florida State University.

H. Leslie Furr, Ph.D., is an associate professor and program director of Hotel and Restaurant Management at Georgia Southern University.

Alex M. Susskind, Ph.D., is an assistant professor in the School of Hotel Administration at Cornell University.

The authors contributed equally to the preparation of this article; their names are presented in alphabetical order. 


\begin{abstract}
In an attempt to create a behavioral profile of pleasure travelers segmented based on Internet use, 5,319 pleasure travelers were interviewed. Initially, the respondents were classified as an Internet user or Internet nonuser based on whether or not they would use the Internet to seek travel related information. Using discriminant analysis, chi square, and analysis of variance statistical techniques, a profile of demographic and behavioral characteristics was created. The results of this study suggest that people who use the Internet to search for travel-related information are likely to be people who are (a) collegeeducated owners of computers, (b) less than 45 years of age, (c) stay more often in commercial lodging establishments, and (d) spend more money each day while traveling. Implications for marketing managers and future research are discussed.
\end{abstract}




\section{Predicting a Behavioral Profile for Pleasure Travelers on the Basis of Internet Use Segmentation}

This article identifies three mutually dependent congregations-academic researchers, marketing managers, and pleasure travelers — who are not ordinarily perceived as possessing common, much less interdependent, interests. A variety of factors serve as stimulants for the growing utilization of the Internet by these groups. First, the Internet is recognized currently as the "world's largest repository of on-line digital information" (Williams et al. 1996). Second, new systems for searching the Internet commercialize the increasingly user-friendly nature of this information behemoth. Last of all, the Internet is now more accessible and less expensive than ever before (Burke 1997).

The Internet's user base is large because it is one of the most popular mechanisms available to marketers, retailers, and manufacturers alike (Burke 1997; Peterson, Balasubramian, and Bronnenberg 1997). This medium also acts as a viable alternative to traditional marketing channel intermediaries (Burke 1997), which benefits the pleasure traveler and the hospitality marketing professionals. Millions of individuals use online Internet services from their homes, organizations, and institutions, as the popularity of Internet use continues to escalate at a steady rate (Au and Hobson 1997). Specifically, the most recent estimate published by the Travel Industry Association of America (TIA) reported over 50 million adult Internet users in 1997, showing a 10\% increase from North American users in 1996 (TIA 1997).

The increased demand for information flow is created by the global marketplace decision makers who are responsible for the planning of various management processes. Some researchers believe this form of information transfer can be accomplished only through computer technology intermediaries, such as the Internet (Bauwens 1995). For instance, the Internet can be used to acquire information on products and services regardless of the classification as either "search or experience goods" (Peterson, Balasubramian, and Bronnenberg 1997, p. 334). However, the service characteristics in terms of purchase cost and frequency, value proposition, and the level of differentiation are likely to influence an individual's Internet search behavior for that item (Deighton 1997; Peterson, Balasubramian, and Bronnenberg 1997). An informational torrent is emerging about the Internet and its utility as an 
information medium (December 1996). Yet, it is difficult to clearly grasp the relationship between the Internet users, Internet providers/marketers, the emerging technology (Newhagen and Rafaeli 1996; Peterson, Balasubramian, and Bronnenberg 1997), and the long-term implications of the Internet as a marketing tool (Burke 1997; Deighton 1997).

The results of recent attempts to profile Internet users' characteristics suggest that Internet users tend to hold higher educational degrees and report higher levels of income than nonusers (Furr and Bonn 1998; Schonland and Williams 1996; TIA 1997). While these general findings significantly increase our understanding of the Internet user as a pleasure traveler, it appears that more issue-specific investigations are required to identify how this information could benefit the marketing community. For example, would it be beneficial to destination marketers to determine the differences in Internet users' preferences for travel and tourism services? If specific destinations or "destination types" are investigated more often by Internet users, as opposed to Internet nonusers, this knowledge permits consumers, service providers, and marketing professionals to efficiently contact particular market segments through the Internet. Consequently, one challenge for this inquiry is to investigate pleasure traveler destination selections and activities based on the Internet user/nonuser dichotomy. In addition, Internet user/nonuser segmentation could be expanded to form a customer profile based on common patterns of destination selections, activity preferences, demographics, and behavioral characteristics of these pleasure travelers.

\section{Developing a Consumer Profile}

The use of customer profiles permits marketing professionals and service providers to assemble services in a manner best suited to a specific consumer group's characteristics (Mazanec 1992), such as size and cost to segment (Kotler 1991) and preferences and perceptions (Etzel and Woodside 1982; Goodrich 1978; Woodside and Pitts 1976). It is also reasonable to assume that the explanation for a traveler's inclination to choose a particular destination type (i.e., nature based or activity based) depends on other selection factors such as cost, safety, seasonality, and consumer accessibility (Bonn, Furr, and Uysal 1992; Morrison et al. 1996; Qu and Li 1997). Ultimately, marketing strategists apply customer 
profiles as a mechanism to identify consumer preferences in primary, secondary, and tertiary markets (Court and Lupton 1997; Morrison et al. 1996).

\section{Research Questions}

The study reported here investigated the travel behavior of Internet users and nonusers in the pleasure travel market. Specific sociodemographic and behavioral differences of tourists and travelers who use the Internet (users) were compared to those who do not use the Internet (nonusers) to gather travel information. Additionally, all respondents provided information based on the following background variables: (a) educational level, (b) income, (c) age, (d) daily expenditures while traveling, and (e) computer access. Each respondent was asked to indicate his or her participation in a series of tourismrelated activities that were grouped in the following manner: (a) sightseeing, (b) attractions, (c) museums, (d) sports attendance, (e) evening activities, (f) shopping, (g) taking a cruise, (h) outdoor activities, and (i) performance arts attendance. The specific research questions were the following:

Research Question 1: What differences in demographic and behavioral characteristics exist between Internet users and nonusers?

Research Question 2: Which demographic and behavioral characteristics are statistically significant?

Research Question 3: Which travel-related characteristics, sociodemographics, and behavioral responses are most effective in predicting a profile for the Internet users and nonusers?

\section{Method}

During 1996, professional surveyors interviewed 6,724 travelers during their recent trip to the Tampa Bay region of Florida. Using a randomized day/site/time sampling frame, area visitors were asked to complete a 10-minute interview. Of those contacted, $90 \%(n=6,052)$ completed the personal interviews. A total of 5,319 participants indicated that their primary trip purpose was for pleasure; while 
the remaining 733 indicated their trip purpose was for business or some other nonleisure purpose and were excluded from further analyses.

During the scheduled interview, the research participants responded to queries from a standard questionnaire that addressed specific details concerning the respondent's recent trip, including his or her primary destination and preferred accommodation types. Additional inquiry assessed the participants' demographic profile and Internet use.

Categorization of the participants' Internet use was accomplished by participants' responses to several Internet-related questions included in the survey. Participants were first asked, "Do you currently have a personal computer at home," and "If yes, do you use an online computer service?" All participants were then asked, "Would you use the Internet to request information on potential vacation destinations?" The participants' binary response to this question (yes or no) indicated their propensity to use the Internet to gather information about potential vacation destinations. All participants were classified as either Internet users or nonusers based on their response to this question. This classification approach was selected to provide a foundation for building profiles of Internet users.

\section{Analyses}

It is common to use an intuitive strategy to compare characteristics in marketing studies that are attempting to define a particular consumer group's behavioral profile. Often success or failure for a commercial project is based on subjective decision making of a marketing manager. Even the most experienced marketing managers recognize that the increased complexity of today's marketing decisions tax their ability to make informed decisions when so many resources are at risk.

The problem that faces any marketing manager who has access to a collection of variables such as education level and a person's television viewing habits is to accurately distinguish between mutually exclusive groups (in this example, those who do watch the program compared to those who never watch the program). If the marketer can identify which variables (i.e., educational level attained) are important 
for distinguishing the watchers from the nonwatchers, the researcher would be on the way to developing a procedure for predicting group membership based on a grouping variable (watching television programs). Three statistical methods were employed to answer the research questions outlined above. In this case, a data reduction statistical technique was deemed the appropriate initial analysis choice since the data collection process produced over 5,000 cases that consisted of 50 variables for each case. Discriminant analysis, first introduced by Sir Ronald Fisher, is the statistical technique most commonly used to investigate problems that present a collection of variables such as income, age, and marital status, when the researcher intends to distinguish between two or more mutually exclusive groups. It is an especially useful technique when the research intends to develop a procedure for predicting group membership for new cases whose group membership is not yet determined (Norusis 1988), while cluster analysis generally relies on predetermined groupings.

A stepwise discriminant analysis was performed as an exploratory tool, using Internet users and nonusers as the grouping variable, to discover which variables are most important for distinguishing between the mutually exclusive Internet user and nonuser groups. This procedure is a first step for predicting group membership and subsequent consumer-profile development for new pleasure travelers whose Internet affiliation is not known. Second, global chisquare tests of sample population variances were applied to the categorical and nominal data as identified by the discriminant analysis (i.e., educational level, Tampa information, computer use, propensity to book a trip on the Internet, sightseeing, museum attendance, and shopping as an activity). The chi-square statistic (i.e., crosstabulations) was chosen to test these noncontinuous data variables because of its proven ability to accurately evaluate the discrepancy between a set of observed frequencies and a set of expected frequencies.

The third step involved the use of a one-way analysis of variance (ANOVA) applied to those variables representing continuous data (i.e., expenditures on ground transportation). The fourth and final step was to incorporate other salient variables into the research process, which highlighted statistically significant differences between users and nonusers. Information from all four steps was used to mold a 
consumer profile of the 1996 Tampa, Florida, pleasure traveler who would use the Internet to collect travel information.

\section{Results}

The first step in discriminant analysis is to select cases and variables to be included in the computations. One important variable, income level, was not introduced into the analysis because of the large number of respondents who chose not to respond to the question. Ultimately, 31 variables (agent use, attraction visit, cruise, education level, daily average expenditures, Tampa information media, origin of visitor by state, lodging expenditure, marital status, museum visitor, outdoor recreation enthusiast, Tampa overnight stay, performance-music, previous visitor to Florida, previous visitor to Tampa, length of stay, used Tampa airport, party size, overnight stay at commercial lodging, food expenditures by group, food expenditures in restaurants, sporting events fees, special event fees, sightseers, nighttime entertainment, ground transportation charges, shopping expenditures, other daily expenses, would book trips on the Internet, out of state, and computer use) were introduced as possible predictor or independent variables while the Internet user/nonuser responses were used as the grouping or dependent variable for this procedure.

The effectiveness of the discriminant function is often related to the percentage of cases that are classified correctly. In this case, $87.6 \%$ of the original grouped cases were correctly classified (see Table 1). This percentage of grouped cases is far above any group classification percentage that one would expect by chance. The percentage of cases correctly classified is only one of several indicators of the effectiveness of the discriminant function. Another gauge of effectiveness is the comparison of betweengroups variability to within-groups variability. The ratio of the between groups variability to the withingroups variability is expressed as an eigenvalue. In general, large eigenvalues are associated with "good" discriminant functions. In this case, the relatively large eigenvalue (1.583) supports the case for an effective discriminant function (see Table 2). The Canonical Correlation (reported in Table 2) is a 
measure of the degree of association between the discriminant scores and the groups and, in this case, represents the proportion of the total variance attributable to the differences among the groups.

In the two-group situation, a Wilks's lambda of .387 (reported in Table 3) indicates that there is a high level of variability between the user and nonuser groups, and a limited level of variability exists within these groups. Based on this lambda score, it appears unlikely that the respondents who would use the Internet to gather travel-related information, in comparison to those who would not use this medium, have the same means on the discriminant function. The interpretation of the coefficients for the discriminant function is similar to multiple regression coefficients in that the variables in both cases are correlated. Therefore, it is not possible to assess the importance of a single variable with that technique. However, when the coefficients are standardized to adjust for unequal means and standard deviations, it is possible to determine which variables generate large or small function values. Accordingly, the Internet user group produced larger function values in terms of computer use, Internet booking, education, and receiving information on Tampa (see Table 4). The relative order and function values of the predictor variables suggest that the respondents' tendency to book trips on the Internet and their level of education are the best discriminatory predictors available to researchers for this particular study.

The initial chi-square analyses were conducted on the nine predictor variables, which were selected by the successful discriminant function as the best set of variables to identify the differences between the Internet user and nonuser groups. The analyses revealed significant results when the predictor variables of age, education, museum attendance, sightseeing, computer use, Internet booking, and acquiring information about Tampa were contrasted by user and nonuser classification in Table 5. As anticipated, age, education, computer use, Internet booking, and information seeking on Tampa, c2(1) = $84.146, \mathrm{p}<.001 ; \mathrm{c} 2(1)=256.33, \mathrm{p}<.001 ; \mathrm{c} 2(1)=15.024, \mathrm{p}<.001 ; \mathrm{c} 2(1)=16.39, \mathrm{p}<.001 ; \mathrm{c} 2(1)=$ $1811.155, \mathrm{p}<.001 ; \mathrm{c} 2(1)=2675.162, \mathrm{p}<.001 ;$ and $\mathrm{c} 2(1)=86.509, \mathrm{p}<.001$, respectively, were statistically significant.

To build a useful profile of the Internet user group, additional information on each of the predictor variables was related to the user group. A preliminary profile review of the predictor variables 
revealed that $71.6 \%$ of the Internet user group were less than 45 years of age and that $62.6 \%$ of the Internet User group were college graduates. Furthermore, Internet users compared to nonusers were (a) less likely to be sightseers, (b) more likely to collect information about Tampa prior to their trip, and (c) more likely to visit area museums upon their arrival in Tampa.

The only continuous data predictor variable identified by the discriminant analysis was expenditures on ground transportation. The one-way ANOVA of this variable revealed that Internet users spent significantly more money per day, on the average $(\$ 16.52)$, than the nonusers $(\$ 9.90), F=45.50, p$ $<.001, \mathrm{~h} 2=.009$ (see Table 6). Reported family income, another continuous data variable, was the only demographic characteristic that was not included in the original discriminant function. A discussion of this variable as it relates to Internet user/nonuser groups has been included here because it highlights the economic impact differences between the Internet user and nonuser groups to the Tampa area. The Internet users group represents a substantial portion of all the travelers who reported a family income greater than $\$ 40,000$. Approximately $45 \%$ of the Internet users' group spent at least one commercial overnight in Tampa as opposed to $31 \%$ of the Internet nonusers' group. Chi-square tests for income among Internet users and nonusers are reported in Table 7.

Several related expenditure-based variables added additional insight into our vision of the Internet users' group profile. The three most significant indicators of economic impact among the Internet users' group on the Tampa area included the total average daily expenditure, overnight lodging expenditure, and expenditures made while shopping. Table 8 outlines the average expenditures for the Internet users' and nonusers' groups. In each case, the Internet users' group outspent the nonusers' group by a statistically significant amount (see Table 9, Table 10, and Table 11). Since most destination areas attempt to attract travelers who are more likely to have the greatest economic impact (Uysal, Fesenmaier, and O’Leary 1994), it is not only appropriate but also necessary to develop a customer profile that relates the spending habits of tourists. As noted in prior research, use of the Internet in marketing processes will most likely result in a redistribution of revenues among channels or among members within a channel (Hagel and Eisenmann 1994). Behavioral factors such as average daily expenditures, family income, and whether or 
not travelers choose to spend the night at commercial lodging properties often prove to be useful in the design of economically motivated strategic marketing plans.

\section{Discussion}

These findings suggest that academic researchers and marketing managers could develop consumer-profileoriented Internet marketing campaigns based on pleasuretravelers' tendency to use the Internet to book pleasure trips. This Internet user group's potential for an increased economic impact on destination areas would be consistent with the findings of Peterson, Balasubramian, and Bronnenberg (1997) who stated that consumers are likely to view infrequent, high-involvement purchases differently than frequent, low-involvement purchases. The Internet could be used to present multilevel, in-depth information to pleasure travelers needing to make high-involvement purchases such as long distance travel plans, rather than having them rely on limited information presented in traditional static ads and brochures.

The Internet advertising option offers this particular consumer group a customized travel-related information format that enhances the service selection process in the privacy of the individual's home. Combining information on visitor's Internet use preferences with their individual sociodemographic characteristics (and to a certain extent with their choice of activities during their travel experience) serves as a useful mix of market segmentation information for identifying marketing strategies that would appeal to the Internet oriented pleasure traveler. In addition, the global nature of the Internet would enable marketing managers to contact international visitors who travel during specific seasons of the year (e.g., the French in August) and who participate in specific activities within a destination.

\section{Implications For Future Research}

Future research should address the regional characteristics of Internet users as a potentially useful characteristic experiences through the creation and promotion of customized packages that are bundled with activities and services sought most often by diverse pleasure travel populations. 
Another issue of Internet use in marketing processes that deserves additional research attention is the area of Internet apprehension. The extent to which individuals are uneasy about using the Internet for travel- and tourism-related purchases is likely to influence the Internet's effectiveness as a marketing channel. In this investigation, approximately $60 \%$ of the respondents indicated that they do not or would not use the Internet to gather travel- and tourism-related information. At this point, it is not clear what influenced their choices to gather consumer information from sources other than the Internet. A substantial body of literature exists that examines individuals' communication apprehension in public and group settings, yet little research exists to explain how apprehension concerning Internet communication influences consumer behavior and marketing processes. This area should be explored to further our understanding of the Internet as a new marketing opportunity.

\section{Limitations}

The classification of Internet users versus nonusers was limited to a binary response of those who reported they would use the Internet to gather travel- and tourism-related information. This classification does not account for levels of use, such as heavy users or light users. It is quite possible that the "level of usage" is significantly related to the characteristics profiled in this investigation. Additional categories of Internet use should be explored to further classify the profile of Internet users. Along similar lines, the extent to which individuals are connected to Internet/computer technology is likely to influence Internet use. It is possible that those who possess more advanced technological capabilities would be more likely to use advanced Internet services. Most likely, as individuals move into higher levels of computer sophistication, their level and degree of comfort using Internet technology will increase as well. These issues should be further explored in future investigations of this type.

Lastly, it also should be noted that this investigation did not examine consumers who had specifically made a traveler tourism-related purchase over the Internet. It merely examined respondents who indicated they would use the Internet to gather travel- and tourism-related information. While this is a useful first step toward an understanding of Internet use behavior, it would be beneficial to examine 
respondents who had previously used the Internet to make purchases of items such as vacation packages, airline tickets, lodging accommodations, or rental cars. Further categorization of Internet use behavior is likely to lead to an even greater understanding of how the Internet can be used as a marketing tool for travel- and tourism-related services.

\section{Conclusion}

This sample indicated that the Internet is a feasible means for distributing travel-related information to widespread markets. Furthermore, today's destination marketing organizations should note two elements outlined in this article: first, a sizable (and expanding) percentage of the traveling public already uses the Internet to gather travel information (TIA 1997); and second, the people who use the Internet to search for information are likely to be people who are (a) college educated owners of computers, (b) less than 45 years of age, (c) stay more often in commercial lodging establishments, and (d) spend more money each day while traveling.

Employing marketing strategies that utilize the Internet as a tourism promotional medium can attract potential visitors through a marketing channel that is in its early stages of development (Deighton 1997). Future research should compare the per person cost of traditional marketing methods to those of Internet promotions to determine the cost effectiveness of including the Internet as a viable marketing tool (cf. Butterfield, Deal, and Kubursi 1998). This would allow tourism destinations to expand their current marketing practices into "virtual marketing” (Burke 1997; Hagel and Sacconaghi 1996) and perhaps reach potential visitor groups that are not motivated by typical advertising campaigns. Destination tourism areas prefer to attract visitors who are capable of contributing to a greater economic impact on the destination area. In addition, these same destination markets are rarely offered the opportunity to increase attendance by more than an incremental amount. A campaign that targets a potentially lucrative population through new technology such as the Internet could be utilized to broaden shoulder seasons or bolster off-season demand by customizing the Internet-oriented marketing campaigns to specific visitor types. Future research should explore the application of Internet promotions to all potential travel markets including, 
but not limited to, such groups as the conventions and meetings market, festivals and event attendees, and visitors seeking nature-based experiences. 


\section{References}

Au, N., and J.S.P. Hobson (1997). "Gambling on the Internet: A Threat to Tourism?” Journal of Travel Research, 35 (Spring): 77-81.

Bauwens, M. (1995). “Knowledge Transfer Theory and Practice.” The Information Advisor, 7 (6): 1-8.

Bonn, M. A., H. L. Furr, and M. Uysal (1992). "Seasonal Variation of Coastal Resort Visitors: Hilton Head Island.” Journal of Travel Research, 31 (Summer): 50-56.

Burke, R. R. (1997). “Do You See What I See? The Future of Virtual Shopping.” Journal of the Academy of Marketing Science, 25: 352-60.

Butterfield, D. W., K. R. Deal, and A. A. Kubursi (1998). "Measuring Returns to Tourism Advertising." Journal of Travel Research, 37 (August): 12-20.

Court, B., and R. A. Lupton (1997). "Customer Portfolio Development: Modeling Destination Adopters, Inactives, and Rejecters.” Journal of Travel Research, 36 (Summer): 35-43.

December, J. (1996). "Units of Analysis for Internet Communication.” Journal of Communication, 46: $14-38$.

Deighton, J. (1997). “Commentary on 'Exploring the Implications of the Internet for Consumer Marketing."” Journal of the Academy of Marketing Science, 25: 347-51.

Etzel, M., and A. Woodside (1982). "Segmenting Vacation Markets: The Case of the Distant and NearHome Traveler.” Journal of Travel Research, 20 (Spring): 10-14.

Furr, H. L., and M. A. Bonn (1998). “The Internet and the Hospitality Marketing Professional.” Journal of Applied Hospitality Management, 1: 60-69.

Goodrich, J. (1978). "The Relationship between References for Perceptions of Vacation Destinations: Application of a Choice Model.” Journal of Travel Research, 16 (Fall): 8-13. 
Hagel, J., III, and T. R. Eisenmann (1994). "Navigating the Multimedia Landscape.” The McKinsey Quarterly, 30 (3): 39-55.

Hagel, J., III, and A. M. Sacconaghi (1996). "Who Will Benefit from Virtual Information.” The McKinsey Quarterly, 32 (3): 22-37.

Kotler, P. (1991). Marketing Management: Analysis, Planning, Implementation, and Control. 7th ed. Englewood Cliffs, NJ: Prentice Hall.

Mazanec, J. (1992). “Classifying Tourists into Market Segments: A Neural Network Approach.” Journal of Travel and Tourism Marketing, 1 (1): 39-59.

Morrison. A. M., C. G. Braunlich, L. A. Cai, and J. T. O’Leary (1996). “A Profile of the Casino Resort Vacationer." Journal of Travel Research, 35 (Fall): 55-61.

Morrison, A. M., P. L. Pearce, G. Moscardo, N. Nadkarni, and J. T. O’Leary (1996). “Specialist Accommodation: Definition, Market Served, and Roles in Tourism Development.” Journal of Travel Research, 35 (Summer): 18-25.

Newhagen, J. E., and S. Rafaeli (1996). "Why Communication Researchers Should Study the Internet: A Dialogue." Journal of Communication, 46: 4-13.

Norusis, Marija J. (1988). SPSS/PC+Advanced Statistics V2.0. Chicago, IL: SPSS.

Peterson, R. A., S. Balasubramian, and B. J. Bronnenberg (1997). "Exploring the Implications of the Internet for Consumer Marketing.” Journal of the Academy of Marketing Science, 25 (4): 329-46.

Qu, H., and I. Li (1997). "The Characteristics and Satisfaction of Mainland Chinese Visitors to Hong Kong.” Journal of Travel Research, 35 (Spring): 37-41. 
Schonland, A. M., and P. W. Williams (1996). "Using the Internet for Travel and Tourism Survey Research: Experiences from the Net Traveler Survey." Journal of Travel Research, 35 (Fall): 8187.

Travel Industry Association of America (1997). “Travelers Use of The Internet 1997: Executive Report.” Washington, DC: Travel Industry Association of America.

Uysal, M., D. R. Fesenmaier, and J. T. O’Leary (1994). “Geographic and Season Variation in the Concentration of Travel in the United States.” Journal of Travel Research, 32 (Winter): 61-64.

Williams, P. W., P. Bascombe, N. Brenner, and D. Green (1996). "Using the Internet for Tourism Research: ‘Information Highway or Dirt Road?’”Journal of Travel Research, 34 (Spring): 63-70.

Woodside, A., and R. Pitts (1976). "Effects of Consumer Lifestyles, Demographics, and Travel Activities on Foreign and Domestic Travel Behavior.” Journal of Travel Research, 14 (Winter): 13-15. 
Table 1. Classification results.

\begin{tabular}{|c|c|c|c|c|}
\hline & \multirow[b]{2}{*}{ Internet Request } & \multicolumn{2}{|c|}{$\begin{array}{l}\text { Predicted Group } \\
\text { Membership }\end{array}$} & \multirow[b]{2}{*}{ Total } \\
\hline & & Yes & No & \\
\hline Original count & $\begin{array}{l}\text { Yes } \\
\text { No }\end{array}$ & $\begin{array}{r}1,116 \\
36\end{array}$ & $\begin{array}{r}622 \\
3,518\end{array}$ & $\begin{array}{l}1,738 \\
3,554\end{array}$ \\
\hline Percentage & $\begin{array}{l}\text { Yes } \\
\text { No }\end{array}$ & $\begin{array}{r}64.2 \\
1.0\end{array}$ & $\begin{array}{l}35.8 \\
99.0\end{array}$ & $\begin{array}{l}100 \\
100\end{array}$ \\
\hline
\end{tabular}

Note: $87.6 \%$ of original grouped cases were correctly classified.

Table 2. Canonical discriminant functions I.

\begin{tabular}{lcccc}
\hline Function & Eigenvalue & $\begin{array}{c}\text { Percentage } \\
\text { of Variance }\end{array}$ & $\begin{array}{c}\text { Cumulative } \\
\text { Percentage }\end{array}$ & $\begin{array}{c}\text { Canonical } \\
\text { Correlation }\end{array}$ \\
\hline 1 & $1.583^{\circ}$ & 100.0 & 100.0 & .783 \\
\hline
\end{tabular}

a. One (the first) canonical discriminant function was used in the analysis.

Table 3. Canonical discriminant functions II.

\begin{tabular}{lcccc}
\hline \hline $\begin{array}{l}\text { Test of } \\
\text { Function }\end{array}$ & $\begin{array}{c}\text { Wilks's } \\
\text { Lambda }\end{array}$ & $\begin{array}{c}\text { Chi- } \\
\text { Square }\end{array}$ & $\begin{array}{c}\text { Degrees of } \\
\text { Freedom }\end{array}$ & Significance \\
\hline 1 & .387 & 4622.332 & 9 & $p<.0001$ \\
\hline
\end{tabular}

Table 4. Standardized canonical discriminant function coefficients.

\begin{tabular}{lc}
\hline Predictor Variables & Function 1 \\
\hline Age-2 & .056 \\
Education & -.109 \\
Museum & -.039 \\
Sightseeing & -.042 \\
Ground transportation & -.050 \\
Computer use & .554 \\
Internet booking & .806 \\
Shopping & .042 \\
Information-Tampa & .070 \\
\hline
\end{tabular}


Table 5. Chi-square analysis of attraction groupings by pleasure travelers who would or would not seek travel information on the internet.

\begin{tabular}{|c|c|c|c|c|c|c|c|c|}
\hline \multirow[b]{3}{*}{ Variable } & \multicolumn{4}{|c|}{ Use the Internet to Seek Travel Information } & \multirow[b]{3}{*}{$\chi^{2}$ Value } & \multirow[b]{3}{*}{$d f$} & \multirow[b]{3}{*}{$p$} & \multirow[b]{3}{*}{ eta } \\
\hline & \multicolumn{2}{|c|}{ Yes } & \multicolumn{2}{|c|}{ No } & & & & \\
\hline & $n$ & $\%$ & $n$ & $\%$ & & & & \\
\hline $\begin{array}{l}\text { Age, } n=5,106 \\
44 \text { or younger } \\
45 \text { or older }\end{array}$ & $\begin{array}{r}1,231 \\
489\end{array}$ & $\begin{array}{l}71.6 \\
28.4\end{array}$ & $\begin{array}{l}1,979 \\
1,407\end{array}$ & $\begin{array}{l}58.4 \\
41.6\end{array}$ & 84.14 & 1 & .000 & .128 \\
\hline $\begin{array}{l}\text { Education, } n=5,026 \\
\text { College degree or more } \\
\text { Less than a college degree }\end{array}$ & $\begin{array}{r}1,072 \\
640\end{array}$ & $\begin{array}{l}62.6 \\
37.4\end{array}$ & $\begin{array}{r}1,287 \\
133\end{array}$ & $\begin{array}{l}38.8 \\
62.1\end{array}$ & 256.33 & 1 & .000 & .226 \\
\hline $\begin{array}{l}\text { Museum, } n=5,186 \\
\quad \text { No } \\
\text { Yes }\end{array}$ & $\begin{array}{r}1,445 \\
293\end{array}$ & $\begin{array}{l}83.1 \\
16.9\end{array}$ & $\begin{array}{r}3,004 \\
444\end{array}$ & $\begin{array}{l}87.1 \\
12.9\end{array}$ & 15.02 & 1 & .000 & .054 \\
\hline $\begin{array}{l}\text { Sightseer, } n=5,292 \\
\quad \text { No } \\
\text { Yes }\end{array}$ & $\begin{array}{r}1,319 \\
419\end{array}$ & $\begin{array}{l}75.9 \\
24.1\end{array}$ & $\begin{array}{r}2,868 \\
686\end{array}$ & $\begin{array}{l}80.7 \\
19.3\end{array}$ & 16.31 & 1 & .000 & .056 \\
\hline $\begin{array}{l}\text { Computer use, } n=5,292 \\
\quad \text { No } \\
\text { Yes }\end{array}$ & $\begin{array}{r}172 \\
1,566\end{array}$ & $\begin{array}{r}9.9 \\
90.1\end{array}$ & $\begin{array}{r}2,564 \\
990\end{array}$ & $\begin{array}{l}72.1 \\
27.9\end{array}$ & $1,811.15$ & 1 & .000 & .585 \\
\hline $\begin{array}{l}\text { Internet booking, } n=5,292 \\
\text { No } \\
\text { Yes }\end{array}$ & $\begin{array}{r}645 \\
1,093\end{array}$ & $\begin{array}{l}37.1 \\
62.9\end{array}$ & $\begin{array}{r}3,521 \\
33\end{array}$ & $\begin{array}{r}99.1 \\
.9\end{array}$ & $2,675.16$ & 1 & .000 & .711 \\
\hline $\begin{array}{l}\text { Information on Tampa, } n=5,275 \\
\quad \text { No } \\
\text { Yes }\end{array}$ & $\begin{array}{r}1,175 \\
557\end{array}$ & $\begin{array}{l}67.8 \\
32.2\end{array}$ & $\begin{array}{r}2,818 \\
725\end{array}$ & $\begin{array}{l}86.5 \\
20.5\end{array}$ & 86.50 & 1 & .000 & .128 \\
\hline
\end{tabular}


Table 6. One-way ANOVA comparing respondents' ground transportation expenditures to internet information users or nonusers

\begin{tabular}{|c|c|c|c|c|c|c|}
\hline \multirow{2}{*}{$\begin{array}{l}\text { Ground Transportation by } \\
\text { Request Information }\end{array}$} & \multicolumn{4}{|c|}{ Descriptive Statistics } & & \\
\hline & & $n$ & $M$ & $S D$ & & \\
\hline \multirow[t]{3}{*}{$\begin{array}{l}\text { No } \\
\text { Yes } \\
\text { Total }\end{array}$} & & $\begin{array}{l}3,554 \\
1,738 \\
5,292\end{array}$ & $\begin{array}{r}9.90 \\
16.52 \\
12.07\end{array}$ & $\begin{array}{l}30.28 \\
39.34 \\
33.67\end{array}$ & & \\
\hline & \multicolumn{6}{|c|}{ Analysis of Variance } \\
\hline & Source & Sum of Squares & $d f$ & Mean Square $^{\mathrm{a}}$ & $F$ Value & $p$ \\
\hline $\begin{array}{l}\text { Average expenditures } \\
\text { for ground transportation } \times \\
\text { Internet use }\end{array}$ & $\begin{array}{l}\text { Between groups } \\
\text { Within groups } \\
\text { Total }\end{array}$ & $\begin{array}{l}\quad 51,143.78 \\
5,946,134 \\
5,997,278\end{array}$ & $\begin{array}{r}1 \\
5,290 \\
5,291\end{array}$ & $\begin{array}{r}51,144.78 \\
1,124.03\end{array}$ & 45.50 & .000 \\
\hline
\end{tabular}

a. eta ${ }^{2}=.009$.

Table 7. Chi-square analysis of the income levels by pleasure travelers who would or would not seek travel information on the internet.

\begin{tabular}{|c|c|c|c|c|c|c|c|c|}
\hline \multirow[b]{3}{*}{ Variable } & \multicolumn{4}{|c|}{ Use the Internet to Seek Travel Information } & \multirow[b]{3}{*}{$\chi^{2}$ Value } & \multirow[b]{3}{*}{$d f$} & \multirow[b]{3}{*}{$p$} & \multirow[b]{3}{*}{ eta } \\
\hline & \multicolumn{2}{|c|}{ Yes } & \multicolumn{2}{|c|}{ No } & & & & \\
\hline & $n$ & $\%$ & $n$ & $\%$ & & & & \\
\hline Income, $n=3,575$ & & & & & 147.714 & 1 & .000 & .203 \\
\hline Less than or equal to $\$ 40,000$ & 389 & 29.6 & 1,141 & 50.4 & & & & \\
\hline Greater than $\$ 40,000$ & 925 & 70.4 & 1,120 & 49.6 & & & & \\
\hline Lodging, $n=5,186$ & & & & & 97.378 & 1 & .000 & .137 \\
\hline $\begin{array}{l}\text { Commercial overnight } \\
\text { All others }\end{array}$ & $\begin{array}{l}786 \\
952\end{array}$ & $\begin{array}{l}45.2 \\
54.8\end{array}$ & $\begin{array}{l}1,079 \\
2,369\end{array}$ & $\begin{array}{l}31.3 \\
68.7\end{array}$ & & & & \\
\hline
\end{tabular}

Table 8. Descriptive statistics for average daily, lodging, and shopping expenditures.

\begin{tabular}{|c|c|c|c|c|c|c|}
\hline & \multicolumn{6}{|c|}{ Internet Request } \\
\hline & \multicolumn{2}{|c|}{ Yes $^{a}$} & \multicolumn{2}{|c|}{$\mathrm{No}^{b}$} & \multicolumn{2}{|c|}{ Total $^{\mathrm{c}}$} \\
\hline & Mean & $S D$ & Mean & $S D$ & Mean & $S D$ \\
\hline \multicolumn{7}{|l|}{ Average daily } \\
\hline Expenditures & 243.65 & 254.81 & 177.21 & 195.76 & 199.48 & 219.57 \\
\hline Lodging expenditures & 41.09 & 32.49 & 25.97 & 50.99 & 31.04 & 32.49 \\
\hline Shopping expenditures & 52.39 & 41.10 & 41.10 & 92.12 & 44.88 & 100.23 \\
\hline
\end{tabular}

a. $n=1,738$.

b. $n=3,448$

c. $n=5,186$. 
Table 9. ANOVA table for average daily expenditures by internet user and nonuser groups.

\begin{tabular}{llrrrr}
\hline & Source & Sum of Squares & $d f$ & Mean Square & $F$ Value \\
\hline Average daily expenditures $\times$ & & & & & \\
Internet use & Between groups & $5,100,448$ & 1 & $5,100,448$ & 107.97 \\
& Within groups & $2.4 \mathrm{E}++^{08}$ & 5,184 & $47,236.73$ & \\
& Total & $2.5 \mathrm{E}++^{08}$ & 5,185 & & \\
\hline
\end{tabular}

a. $\operatorname{eta}^{2}=.020$.

Table 10. ANOVA table for lodging expenditures by internet user and nonuser groups.

\begin{tabular}{|c|c|c|c|c|c|c|}
\hline & Source & Sum of Squares & $d f$ & Mean Square ${ }^{a}$ & $F$ Value & $p$ \\
\hline $\begin{array}{l}\text { Average daily lodging } \\
\text { expenditures } \times \text { Internet use }\end{array}$ & $\begin{array}{l}\text { Between groups } \\
\text { Within groups } \\
\text { Total }\end{array}$ & $\begin{array}{r}264,250.3 \\
1.5 \mathrm{E}+{ }^{07} \\
1.5 \mathrm{E}+{ }^{07}\end{array}$ & $\begin{array}{r}1 \\
5,184 \\
5,185\end{array}$ & $\begin{array}{r}264,250.3 \\
2,920.11\end{array}$ & 90.49 & .000 \\
\hline
\end{tabular}

a. eta $^{2}=.017$.

Table 11. ANOVA table for shopping expenditures by internet user and nonuser groups.

\begin{tabular}{|c|c|c|c|c|c|c|}
\hline & Source & Sum of Squares & $d f$ & Mean Square $^{a}$ & $F$ Value & $p$ \\
\hline \multicolumn{7}{|c|}{ Average daily expenditures $x$} \\
\hline Internet use & $\begin{array}{l}\text { Between groups } \\
\text { Within groups } \\
\text { Total }\end{array}$ & $\begin{array}{r}147,464.3 \\
5.2 \mathrm{E}+{ }^{07} \\
2.5 \mathrm{E}+{ }^{07}\end{array}$ & $\begin{array}{r}1 \\
5,184 \\
5,185\end{array}$ & $\begin{array}{c}147,464.3 \\
10019.83\end{array}$ & 14.71 & .000 \\
\hline
\end{tabular}

a. eta $^{2}=.003$. 